\title{
PENGARUH CAMPURAN LIMBAH LUMPUR SEDIMENTASI PAM TERHADAP DAYA DUKUNG TANAH EKSPANSIF DENGAN KADAR YANG BERVARIASI
}

\author{
Ali Aman Siregar, Gina Bachtiar, Hendri Dunan
}

\begin{abstract}
Abstrak
Penelitian ini dilakukan untuk mengetahui tentang pengaruh campuran limbah lumpur sedimentasi PAM dengan kadar yang bervariasi terhadap daya dukung tanah ekspansif. Hasil penelitian ini diduga nilai optimum daya dukung tanah ekspansif yang dicampur limbah lumpur sedimentasi PAM lebih tinggi dari tanah ekspansif asli (kadar lumpur 0\%).

Penelitian ini dilaksanakan di Laboratorium Mekanika Tanah, jurusan Teknik Sipil, Universitas Negeri Jakarta, dilaksanakan pada bulan Desember 2004 sampai dengan Januari 2005. Metode penelitian yang digunakan adalah metode eksperimen di laboratorium, sebagai kelompok uji adalah campuran tanah + lumpur sedimentasi PAM yang mencapai nilai kuat tekan optimum dengan kelompok pembanding adalah nilai daya dukung tanah asli.

Persyaratan analisa data dalam penelitian ini menggunakan Uji Lilliefors untuk menghitung normalitas dan Uji Bartlett untuk menghitung homogenitas. Dengan terpenuhinya persyaratan uji dan sampel tersebut, maka hipotesis penelitian diuji dengan uji t rata-rata satu pihak dengan derajat kebebasan $(d k)=$ $n-1$ dan $\alpha=0,01$. Hasil pengujian menunjukkan bahwa kriteria uji $t$ (hitung) berada pada daerah penerimaan Ho. Hal ini dapat disimpulkan bahwa nilai CBR tanah + lumpur yang maksimum sebesar $41.47 \%$ yaitu terdapat pada tanah + lumpur 20\%, ternyata melebihi dari nilai CBR tanah asli yang sebesar $20.74 \%$. Dengan demikian hipotesis penelitian yang menyatakan: nilai maksimum dari hasil penelitian adalah tanah + lumpur $20 \%$.
\end{abstract}

Kata kunci : limbah lumpur, daya dukung, tanah ekspansif.

\section{PENDAHULUAN}

\section{Ali Aman Siregar}

Alumni Jurusan Teknik Sipil

Fakultas Teknik

Universitas Negeri Jakarta, 13220
Dra. Gina Bachtiar, MT

Staf Pengajar Jurusan Teknik Sipil Fakultas Teknik Universitas Negeri Jakarta, 13220 email : gnbachtiar93@gmail.com
Drs. Hendri Dunant Hamidi, M.Si Staf Pengajar Jurusan Teknik Sipil Fakultas Teknik Universitas Negeri Jakarta, 13220 email : 
Tanah merupakan bagian penting dalam dunia teknik sipil, apalagi bila dikaitkan dengan bangunan yang berada di darat. Setiap bangunan yang ada di muka bumi memerlukan tempat untuk berpijak, agar bangunan tersebut dapat berdiri dengan kokoh, tentunya daya dukung tanah tempat bangunan berpijak sangat besar pengaruhnya.

Kekuatan pada tanah yang dalam dunia teknik sipil disebut dengan Mekanika Tanah menjadi salah mata kuliah pada setiap jurusan Teknik Sipil di setiap Perguruan Tinggi. Setiap bangunan yang akan didirikan perlu mempertimbangkan daya dukung tanah yang akan ditempatinya, karena apabila tidak maka akan menjadi masalah yang sangat besar bagi bangunan tersebut.

Di Indonesia terdapat berbagai jenis tanah dengan karakteristik yang berbeda-beda, salah satu jenis tanah yang terdapat di negeri ini adalah tanah ekspansif. Tanah ini mempunyai sifat kembang susut yang tinggi akibat pengaruh kadar air yang dikandungnya. Apabila kadar air yang dikandungnya tinggi maka pemuaiannya relatif besar dan apabila kadar airnya menurun penyusutannya juga relatif besar dibanding jenis tanah lainnya. Untuk mengatasi masalah ini telah dilakukan berbagai penelitian dengan mencampurnya dengan berbagai zat seperti: semen, abu sekam dan lain-lain. Dalam hal ini penulis mencoba untuk menstabilkan tanah ekspansif dengan limbah lumpur sedimentasi PAM dengan kadar yang bervariasi.

Limbah lumpur sedimentasi PAM banyak didapatkan di tempat pengolahan air minum yang ditangani oleh PAM dalam jumlah yang banyak, karena setiap hari dilakukan pengolahan air dalam jumlah yang sangat banyak. Lumpur ini sudah tidak berguna lagi, tetapi apabila dapat dimanfaatkan untuk keperluan tertentu maka akan sangat berguna bagi kebutuhan manusia, dalam hal ini untuk menstabilkan tanah ekspansif.

Tujuan penelitian ini adalah untuk mengetahui adanya perbedaan daya dukung tanah ekspansif terhadap kadar limbah lumpur sedimentasi PAM 5\%, 10\%, 15\% dan 20\%. Berdasarkan tujuan penelitian tersebut, maka metode penelitian ini adalah metode eksperimen di laboratorium, dengan menggunakan pemadatan standar dan CBR laboratorium.

\section{HASIL DAN PEMBAHASAN}

Pada penelitian ini telah dilakukan beberapa perlakuan terhadap benda uji. Untuk kelompok $A$ adalah tanah asli (lumpur 0\%), kelompok B adalah tanah dengan lumpur 5\%, kelompok $\mathrm{C}$ adalah tanah dengan lumpur $10 \%$, kelompok $D$ adalah tanah dengan lumpur $15 \%$ dan kelompok $E$ adalah tanah dengan lumpur $20 \%$ yang dihitung dari berat tanah. 
Tabel 1. Hasil pengujian CBR tanah asli dan tanah ditambah limbah lumpur sedimentasi PAM dengan persentase $5 \%, 10 \%, 15 \%$ dan $20 \%$

\begin{tabular}{|c|c|c|c|c|c|}
\hline \multirow{2}{*}{ Nomor } & \multicolumn{5}{|c|}{ Nilai CBR } \\
\cline { 2 - 6 } & $\mathbf{A ~ ( 0 \% )}$ & $\mathbf{B}(\mathbf{5} \%)$ & $\mathbf{C}(\mathbf{1 0 \% )}$ & $\mathbf{D}(\mathbf{1 5 \% )}$ & $\mathbf{E}(\mathbf{2 0 \% )}$ \\
\hline 1 & 22.81 & 36.98 & 39.75 & 42.86 & 41.13 \\
\hline 2 & 18.66 & 23.85 & 29.38 & 34.91 & 41.82 \\
\hline 3 & 20.74 & 30.41 & 34.56 & 38.88 & 41.47 \\
\hline SX & 62.21 & 91.24 & 103.68 & 116.64 & 124.42 \\
\hline X & 20.74 & 30.41 & 34.56 & 38.88 & 41.47 \\
\hline S2 & 4.300 & 43.120 & 26.875 & 15.797 & 0.119 \\
\hline S & 2.07 & 6.57 & 5.18 & 3.97 & 0.35 \\
\hline
\end{tabular}

Dilihat dari hasil penelitian di atas, diperoleh daya dukung tertinggi terdapat pada campuran tanah dengan lumpur $20 \%$ yaitu sebesar $41,47 \%$.

Berikut gambar grafik hubungan antara nilai CBR dengan kadar lumpur:

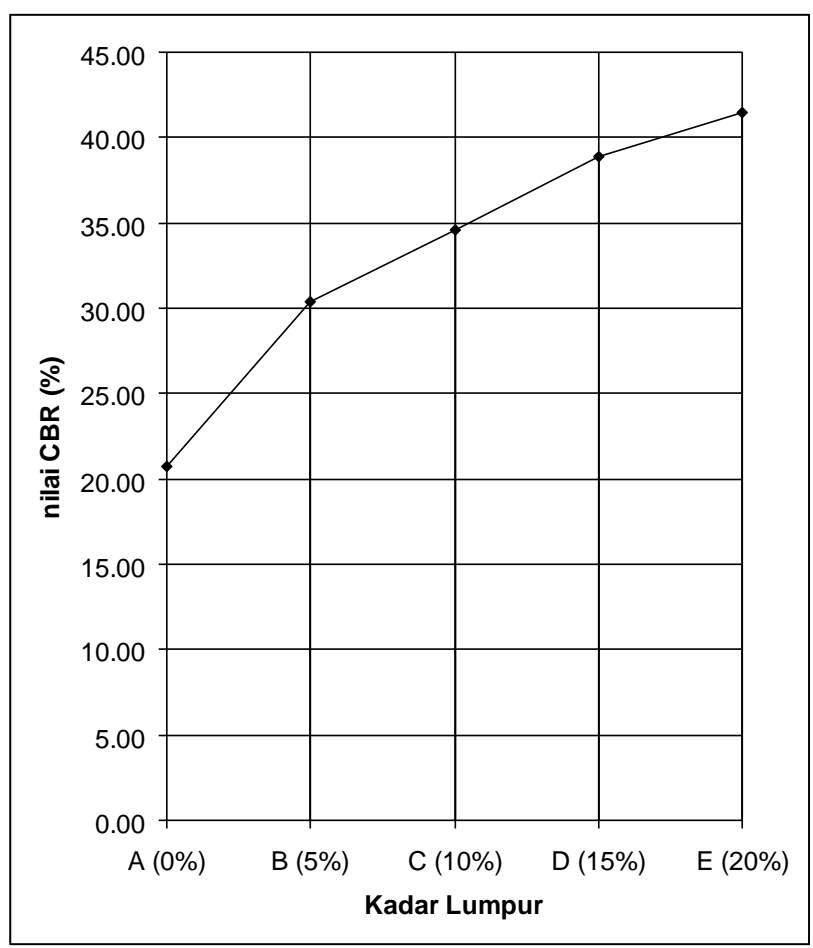

Gambar 1. Hubungan antara nilai CBR dengan kadar lumpur 


\section{KESIMPULAN}

Berdasarkan hasil penelitian didapat kesimpulan sebagai berikut;

1. Terdapat perbedaan nilai daya dukung yang signifikan terhadap kadar lumpur $5 \%, 10 \%, 15 \%$ dan $20 \%$.

2. Nilai daya dukung semua campuran tanah + lumpur lebih tinggi dari daya dukung tanah asli.

3. Semakin banyak kandungan yang terdapat dalam campuran tanah ekspansif maka semakin besar daya dukungnya.

\section{DAFTAR PUSTAKA}

Aim Abdurachim, 1993, Pemanfaatan Limbah Lumpur Sedimentasi Pengolahan Air Bersih PDAM, Jurnal Penelitian Pemukiman Vol IV.

Ari Utami, 2003, Pengaruh Penggunaan Kapur Terhadap Daya Dukung Tanah Ekspansif, Jakarta.

Brosur PAM JAYA Instalasi Buaran, 1995.

Dicky Santosa, Analisis Penggunaan Abu Gosok Dalam Menstabilkan Tanah Ekspansif, Jakarta.

G. Djatmiko Soedarmo-S. J. Edy Purnomo, 1997, Mekanika Tanah I, Kanisius, Bandung.

Hary Christiady Hardiyatmo, 2003, Mekanika Tanah II, Yogyakarta.

L.D. Wesley, 1977, Mekanika Tanah, Jakarta.

Noorzully Septriana,_2002, Studi Stabilisasi Tanah Dengan Semen dan Air Yang Bervariasi, Jakarta.

PT SUCOFINDO, 1993, Report of Analysis, Jakarta.

R. Affandy Hendarmin, 1986, Jalan Raya Jilid I, Jakarta.

Shirley LH, 1987, Geoteknik Dan Mekanika Tanah, (Penyelidikan Lapangan Dan Laboratorium), Nova, Bandung.

SNI 03-1744-1988, 1988, Pengujian CBR Laboratorium, Jakarta.

PB - 0111 - 76, 1976, Pemeriksaan Kepadatan Standar 